\title{
Energy-Efficient Technologies in the Educational Programs of the Architectural Higher Education Schools
}

\author{
Galina B. Zakharova ${ }^{1,2}$, Alexandr I. Krivonogov' ${ }^{2}$, \\ Sergey V. Kruglikov ${ }^{2}$, Alexandr A. Petunin ${ }^{2}$ \\ ${ }^{1}$ Ural State University of Architecture and Art, K. Libknekht str. 23, 620075 \\ Ekaterinburg, Russia, zakharova@usaaa.ru \\ ${ }^{2}$ Ural Federal University, Mira str. 19, 620002 Ekaterinburg, Russia \\ \{g.b.zakharova, a.i.krivonogv, s.v.kruglikov, a.a.petunin\}@urfu.ru
}

\begin{abstract}
The world trends in modern construction correspond to the ecological, rational design, according to "green" standards and applications of the building information modeling - BIM. Herein, we give a short review and some examples of Green, BIM technologies, in different countries. For more effective implementation of "green" building, it is necessary to introduce corresponding thematic in the higher education. Based on a comprehensive analysis of the articles, we described the competencies that a University Graduate must possess, for successful implementation in the industry AEC. Despite the absence of common methods, we developed a practice-oriented approach for teaching students Green BIM technologies and here integration these technologies into the educational process is considered. Some projects of energy-efficient objects, created by students of University of Architecture and Art, meeting requirements of "green" standards, are presented.
\end{abstract}

Keywords: energy-efficient technologies; BIM; "green" standards; Green BIM; education

\section{Introduction}

In recent years, Russia has been paying increasing attention to environmental issues and sustainable development. The Ministry of Natural Resources and Environment of the Russian Federation has developed the strategy for the environmental safety of the Russian Federation for the period up to 2025 and the plan for its implementation. The document determines the level of environmental safety in the territory where lives the most of the Russian population at the present time as unsatisfactory. Fundamental changes in this situation, improving the quality of life and health of the population require joint actions of the state, business, public organizations and the population. 
The Strategy notes that one of the important measures to overcome environmental problems is to foster environmental literacy among the young generation through teaching methods and means of "green" designs, in relevant universities.

In 2018, by decree of the President of the Russian Federation, 12 national projects were adopted in all areas of the country's strategic development, and one of these projects was Ecology. The goal of the project is to improve the environmental situation in Russia and create comfortable conditions for life in the country.

In 2009, The Russian Green Building Council (RuGBC) was created as a member of the World Green Building Council. It is a not-for-profit industry organization dedicated to accelerating development and adoption of market-based «green» building (sustainable building) practices. In accordance with its mission, RuGBC promotes the modernization of the construction industry in accordance with the principles of environmental construction through the creation of standards, methodologies, design solutions, and the union of supporters of the integrated promotion of green technologies and solutions. The instruments of «green» design are passive and active house technologies [1], traditional energy-efficient power generation, use of wind and solar energy, heat pumps, energy efficient controlled lighting, water treatment, solid waste processing, etc.

The world trends in modern construction correspond to the ecological rational design in accordance with green standards and building information modeling BIM [2]. In a review of numerous publications on Green BIM [3], it was noted that the attention of research is focused on environmental indicators at the design stage (more than half of the articles reviewed) and the construction stage (about a third). Few studies concentrated on the development of BIM-based tools for managing environmental performance during the building maintenance, retrofitting, and demolition stages. The authors suggest that BIM for monitoring and managing environmental sustainability over the full life cycle of a building should be developed in future research. Future green BIM tools should include the concept of three $\mathrm{R}$ (reduction, reuse and recycle) in sustainability analysis for new development and modernization projects. It was also noted that the lack of computer tools and the complications of the BIM models are hindering the adoption of green BIM.

Based on an analysis of about 400 articles published from 1999 to 2016 and the 12 most common types of BIM software, the Survey [4] concludes that there is an urgent need for a nexus between BIM and Green Buildings. The study proposed the Green BIM Triangle taxonomy, which indicates that the relationship between BIM and green buildings should be understood based on three dimensions: project phases, green attributes, and BIM attributes. In accordance with this, the following are shown:

1) BIM applications to support the design, construction, operation and retrofitting processes of green buildings. 
2) BIM functions for the analysis of green buildings, such as analysis of energy, emissions and ventilation analysis.

3) The use of BIM to support green building assessments.

4) Research gaps and future research directions in this area. This issue contributes to better alignment BIM development with green building development in the future.

In order for end-users to be involved in the building design process in the early stages to obtain adequate information, the Green 2.0 online system was developed [5]. It is an open platform that leverages advances in information model building (BIM) and energy efficiency modeling tools. The system is integrated with a social network, which allows participants (end users or professionals) to share their views on building design. Social analysis and semantic modeling tools are then used to extract information from these interactions. At the same time, it connects BIM to energy analysis software, which allows users to select various products from the catalog and evaluate the impact of each of them on energy consumption. The platform is aimed at promoting the modern level of technology due to fundamental changes in the ways of joint work of AEC specialists, end users and government politicians throughout the life cycle of the building.

The authors of [6] propose the tool for assessing green building, which extracts the necessary data from BIM models to calculate the green rating and helps the development team to create documentation for obtaining a green certificate (for example, BREEAM) and provides feedback for further assessment. Article [7] assesses the applicability of BIM to optimize building sustainability assessment (BSA) methods. Although BIM is not designed to support sustainable construction, it has great potential: BSA can be simplified with BIM. The results show that using the developed application, it is possible directly and indirectly evaluate most of the criteria using BIM.

Here are a few more specific examples of the effective use of BIM and Green BIM technologies. In [8], a Green BIM case study was developed and Nordic experience was discussed as a source of good practice regarding the implementation of Green BIM. The experience of Finland, which is now the undisputed leader in innovation, is noted. One of the leading investments in Sweden, in Stockholm, implemented in accordance with the BIM concept and sustainability criteria - the largest shopping center in Scandinavia is mentioned. BIM and sustainability are two symbiotic forces that currently span the construction industry around the world. Study [9], using the design of the Hungarian National Sports Center as an example, shows the great potential for dynamic modeling of climate and energy in buildings. A set of calculations was performed, while energy modeling and architectural planning were performed synchronously. Study [10] contains a detailed analysis of the application of BIM technology, energy modeling and life cycle assessment in a project of the Helsinki Music Center. 
The article [11] made a fundamental review of more than 1,500 BIM publications that have been published over the past 25 years by BIM researchers from 65 countries. The growth dynamics of publications, the leading countries (USA, UK, China, Australia), the main trends in global research areas are shown. Of the 12 BIM fields, 3 areas have the most significant contribution: process simulation and monitoring (22\%), building information services (16\%) and standardization $(14 \%)$. In our context, we note that the direction of Education and training is noticeable $-8 \%$.

An important role in ensuring the further more effective development of green technologies in construction is assigned to the education system. Fostering environmental responsibility among youth through teaching Green BIM design methods and tools at architectural and construction universities will improve the environment in the future and ensure a transition to an environmentally-friendly model of economic development. In higher education, there are currently no common standards and approaches. Moreover, most universities in Russia are at the initial stage of introducing Green BIM technologies into the educational process. For the wide spread of the Green BIM technologies, it is necessary to develop educational standards for teaching in universities. But this process is not fast, therefore an architectural and construction universities should find their own forms and methods for the rapid introduction of modern technologies in the educational process.

Aware of all the responsibility to future generations, we have continuously introduced a number of practice-oriented methods of teaching students at the Ural State University of Architecture and Art (USUAA) under the unique interdisciplinary educational program "Applied Informatics in Architecture." Next, we will describe the techniques that we developed and applied in the process of teaching students majoring in computer science-architect. Our graduates, who have the most modern knowledge in the field of environmental design and information modeling, organically introduce these technologies into the practice of building facilities that meet the principles of sustainable development. We will also present a number of projects carried out by students of the Department of Applied Informatics USUAA using BIM and Green BIM technologies and meeting the requirements of "green" standards.

Before that, we present the results of our study on the subject of what competencies a graduate of a modern architectural and construction university should have in order to successfully integrate into a new dynamically developing digital environment and what methods and approaches to teaching have been developed in foreign and Russian universities. 


\section{Overview of BIM Technologies Teaching Methods}

A modern BIM specialist, based on the main property of the BIM model, focused on teamwork in a common information space, should have the main quality - the ability to solve professional problems. Nevertheless, soft skills are equally important, such as, people management, coordination skills, emotional intelligence, focus on customers and negotiation skills. This is part of the list of key competencies of the future for 2020, which was compiled at the Davos World Economic Forum in 2016 as part of the discussion "Competences of the future: what to learn and how to teach." Supplemented by personal qualities, such as analytical abilities, initiative, responsibility, sociability, motivation and focus on effective work, this model of BIM specialist meets modern requirements.

BIM makes fundamental changes in the architectural, engineering and construction industries and therefore affects the requirements for educational process in the relevant areas. Foreign sources devoted to various aspects of BIM show significant experience in teaching, which corresponds to the mature level of BIM development in Europe, USA, Singapore, Australia, etc.

The review [12] systematically presents research methods, data collection, information about disciplines, and educational literature on BIM. Such approaches and teaching methods as joint and active are described; the most popular are project and problem methods. Realistic modeling of projects is used, the nature of BIM as a way of working together pushed the teachers of AEC to implement interdisciplinary models. The conceptual classification of the efforts of a BIM teacher and researchers in higher education systems is given. Six categories of tasks have been developed that reflect a systematic approach to the implementation of BIM education: determining the needs for BIM in universities; identification of basic skills for teaching BIM; development of educational structures BIM; curriculum development; experiments with BIM courses; development of strategies to overcome educational problems.

Non-technological skills of a BIM specialist are studied in the article [13]. It is shown that problems associated with people and processes can impede the success of BIM even more than the technology itself. This points to a new additional set of BIM skills that teachers need to develop in preparing students for a successful future career. Based on an analysis of the literature on non-BIM skills, it is shown how problem-based learning can improve these types of skills and to what extent it can be beneficial in applying BIM. The article uses an interesting abbreviation for assessing the quality of students' answers to poorly structured and open problems, which are usually included in problem education - S.M.A.R.T. (specific, measurable, assignable, realistic, time-based).

Requirements for a BIM specialist on the part of customer companies in the UK construction industry are described in [14]. Customer demand is recognized as a significant motivation and encourages the construction industry to begin the 
transformation and implementation of BIM. Based on numerous case studies and data collection through interviews, several types of competencies are identified as critical success factors. Any BIM-based project should start with EIR (Employer Information Requirement), customer information requirements. EIR should be designed in accordance with the supply chain throughout the project life cycle. According to UK government standards, customers must develop their requirements in three main areas: technical, managerial and commercial.

The study [15] analyzed and compared BIM maturity models. The results showed that there is no holistic model that includes definitions of processes that encompass the entire life cycle of an object and contain measures to evaluate all AEC/FM (facility management) processes. A reference model has been developed to evaluate BIM capabilities in AEC/FM processes, which has been developed iteratively through expert reviews and preliminary research. The results showed that the model is able to identify the BIM capabilities of various AEC/FM processes.

The experience of developing countries [16], which is shown by the example of the Nigerian construction industry, is interesting. As a result of this study, it was found that there is a great need for adequate training of professional specialists in the skills and competencies of using BIM. Professional organizations can apply training methods such as organizing a regular seminar and conference on BIM concepts and applications, creating a BIM academy where professional members can receive proper training on BIM. The educational community is exploring the best ways to integrate BIM into study programs.

In Russia in recent years, the number of publications devoted to the experience of implementing BIM in the educational process has increased significantly. For example, the Samara State University of Architecture and Civil Engineering uses the BIM methodology and the accompanying methodology for integrated project implementation in construction IPD (Integrated Project Delivery) [17]. It is proposed to model such an IPD feature as early involvement in the design and construction process of the project team and general contractor in the educational process through cross-disciplinary course design.

At the Saint-Petersburg State University of Architecture and Civil Engineering, training in collaboration in a BIM project was conducted in the optional format [18]. The course is not compulsory, therefore it allows to improve the balance in the number of participants, is out of schedule and makes it possible to assemble students of different specialties into the study group: architect, specialist in constructions, water supply, heat and gas supply and ventilation, electric networks, estimator and programmer responsible for automation processes. Specialists in techno sphere safety, organization of the construction process, etc., can be involved.

Problems and prospects in Russian universities from the perspective of a software integrator company are discussed in the article [19]. The authors offer practice- 
oriented BIM education and engineering training at architectural universities. All aspects of BIM are shown throughout the entire life cycle of the capital construction project. In accordance with this, requirements and approaches to training are formulated. We draw attention to the noted importance of cooperation between universities with leaders in the construction industry for the development of software and equipment, with integrator companies with practical experience in the development and implementation of BIM.

We also implemented the introduction of new technologies in the educational process of students of the architectural university [20-22]. In the next section, our methods are described in more detail.

\section{Green BIM in the Educational Program "Applied Informatics in Architecture"}

\subsection{Practical-oriented Methods for Teaching Green BIM}

In this section, we describe a comprehensive approach that allowed us successfully teach students the principles of environmental design and information modeling using active and practice-oriented methods. This approach was applied at the USUAA on the Department of Applied Informatics for multidisciplinary specialists in the field of "Applied Informatics in Architecture" and consists of 6 sections described below.

\section{1) The introduction to the CAD course of modern BIM and Green BIM tools}

In the multi semester CAD discipline we were free to include a large number of modern automation tools for the architectural and construction industry. We teach them Autodesk Revit and Graphisoft ARCHICAD for creation of BIM projects, in Navisworks students learn principles of 4D и 5D modeling.

We explain students that the information model is a multidimensional concept. If it is structured as in the work of Pennsylvania University on recommendations for BIM implementation [23], then a lot of BIM scenarios (or BIM Uses) are highlighted, these are components of BIM technologies tied to the planning, design, construction and operation stages. There are 25 scenarios at this resource, some of them are: modeling of existing conditions, cost estimation, design, construction analysis, light analysis, energy analysis, mechanical analysis, LEED compliance assessment, compliance, service planning, building system analysis, planning in case of emergency.

Autodesk 3DS Max and AutoCAD packages are also used in the learning process. Students are able to import 3D models into the Unity 3D and Unreal Engine software environment to organize VR interactive project management in real time. 
Projects in the technique of AR (augmented reality) are also elaborated. To work with a relief and to design infrastructure objects, AutoCAD Civil 3D is used. The development of project concepts is carried out using the InfraWorks 360 platform in order to improve the efficiency of data exchange and collaboration. Data bases such as Autodesk's Vault and CSoft's TDMS for the cataloguing and integration of construction objects and for collective project development were mastered.

\section{2) Discussions of the best world practices in the field of environmental design}

For interactive lessons students prepare topics including the best world examples of «green» architecture. Thus, the projects of architects who work by the criteria of sustainable development were analyzed. These architects were awarded the Pritzker Prize, which is an analogue of the Nobel Prize in the architecture. It should also be noted the international competition LafargeHolcim Awards, which is held since 2005 . The jury evaluates all works according to five main criteria: a holistic, integrated view on the sustainable development, an innovation and ability to replicate simultaneously; ethical standards and social inclusion; resource consumption and environmental indicators; economic feasibility, universality and applicability; contextual and aesthetic impact of the project.

\section{3) Excursions to objects certified according to "green» standards}

We have visited with student's green objects in our city and study features of facilities in other regions. One of the objects was the cottage village Ekodolia near Ekaterinburg to study the experience of building the house of class A+. The house was realized in accordance with the concept of Active House on the basis of the European experience. The main objective of this project is to find a solution for a modern Russian house that meets high requirements of resource saving, ecology and quality of habitat. At the same time, the cost of building and operating a house must be in keeping with capabilities of people.

\section{4) Collaboration with innovative companies}

Throughout the entire period of training students, we established contacts and regularly invited specialists from leading enterprises in the field of building automation "Smart Home", energy-efficient housing construction, developers of Russian green standards Green Zoom and many others.

\section{5) The organization of conferences and roundtables}

We organize scientific conferences and roundtables with the participation of our students and graduates on advanced technologies in the urban environment, practical seminars organized by companies that produce new materials and technologies ("Knauf", "Izover", "Teplit"), in major international exhibitions and conferences in Ekaterinburg ("Innoprom", "Forum 100+"). Within the annual exhibition "The Building Complex of the Big Urals" we have organized the round table on the application of BIM and Green BIM technologies in the Urals region: 
difficulties, effects, prospects; BIM in the education: who teaches and how, what competencies are needed for employers.

\section{6) The participation of students in international and Russian competitions}

Over several years, students of our department took part in the international competition of the Saint-Gobain company for the design of multi-comfort buildings in different countries. In the Autodesk international competition our student Alexander Ivlev in 2012 received the main prize in the nomination "Give the shape to the future" with the project of an eco-house controlled by the automatic system Smart House. In the next section, this project is shown.

\subsection{Innovations and IT in the Construction}

New information technologies make up the basis of the current techno-economic paradigm. Its scientific basis is achievements in artificial intelligence and interdisciplinary approaches. We include innovative technologies in the educational process, explain, show and discuss different cases.

Cloud technologies, with their application the concept of Connected BIM appeared, when all processes, people and technologies are interconnected in the information environment. This technology allows you to quickly and efficiently manage the entire life cycle of an object.

The Smart Home and Smart City technologies are also based on cloud services and Internet of Things (IoT) wireless technology. IoT allows you to organize an independent interconnection of various objects using sensors and wireless networks, as well as control all parameters.

Virtual and Augmented Reality (VR/AR). The user can view the building inside and out, have additional information in infographics and interact with the environment. We have implemented a number of such projects for the innovative promotion of architectural projects.

3D scanning of the terrain, combining data with GIS and formation of 3D model of the object in relation to the terrain. The use of unmanned aerial vehicles to obtain relevant information about the current state of construction. 3D printing of buildings, small architectural forms, etc.

Artificial intelligence has unlimited possibilities for solving optimization problems based on models and algorithms of machine learning and neural networks.

\subsection{Diploma Projects with Green BIM Technologies}

Graduate projects of students of the Applied Informatics department which demonstrate skills in designing of energy-efficient facilities using Green BIM 
technologies are shown here. In some cases, our diploma projects correspond to real objects - industrial, public and apartment buildings. In the Fig. 1 we see the futuristic project of a Smart house (Alexander Ivlev), designed to meet the requirements of environmental friendliness and energy efficiency.

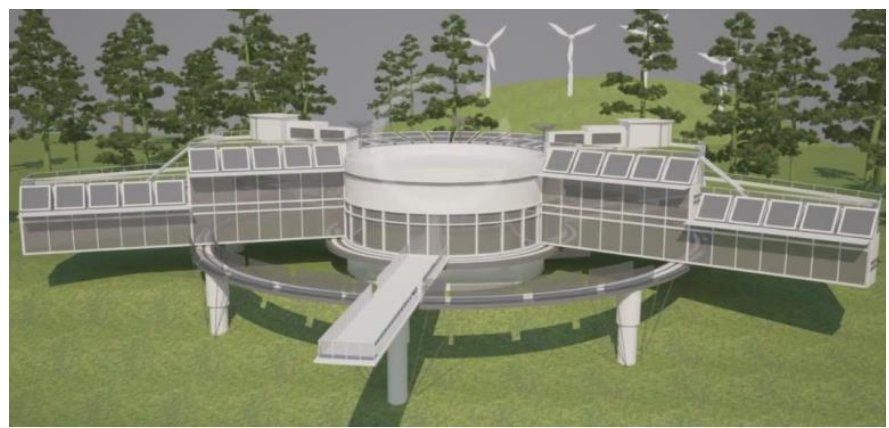

Figure 1

3D-visualization of the "smart" eco-house

For the least impact on the environment, the house is located on five columns, which also facilitate the placement of the building on uneven terrain, which will ensure the stability for the moving structure of the house. The work of the student was directed to a high-quality visualization and he developed a great video clip in After Effects program on the basis of 3DS Max models both the environment and the interior.

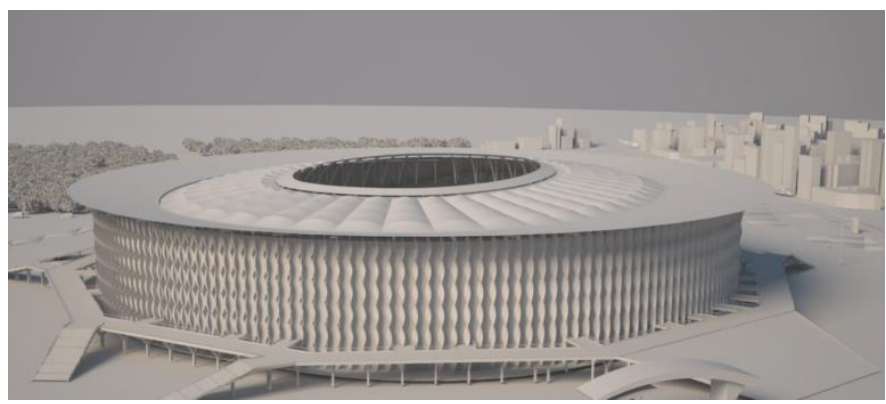

Figure 2

The stadium project in Tokyo

In the diploma work on Fig. 2 (Nadezhda Klyukina), a multifunctional stadium in Tokyo was designed using energy-saving architectural and construction technologies and energy efficient engineering solutions. When the stadium was designing, the attention was paid to the environmental optimization and in particular to the Green Goal program, which is being developed by the initiative of FIFA. In this work, the stadium project has been certified according to the LEED standard. 
The architectural solution of the stadium is made using kinetic architecture, in particular, dynamic facades are offered as an alternative to sunscreens with low thermal conductivity, and also a way to organize the active effective ventilation. The facade was modelled in the Autodesk Revit program with the plug-in Dynamo.

The Autodesk Revit was also used for the information modeling. Along with the digital 3D model for joint development at all stages of the life cycle, the calculation of wind load, the analysis of external flow, the energy audit, the calculation of the heating, ventilation and air conditioning systems was carried out. Autodesk Green Building Studio software was used to conduct energy modeling and evaluate the energy efficiency of the building.

For more in-depth analysis, the following programs were used: Energy Plus for the analyzing of energy expenditure for heating, cooling, ventilation and lighting; Lighting analysis for Revit - for a more accurate analysis of the illumination of the object in accordance with the LEED standard; Green BIM Engineering uses Autodesk Simulation CFD 2014 to analyze the efficiency of ventilation and air conditioning systems, to develop a passive heating/cooling/ventilation, to study the influence of the shape of the building and obstacles on the external wind load; Flow Design - for modeling air flows. To calculate the financial model and investment attractiveness of the project, the software product Alt-Invest was used to prepare, analyze and optimize investment projects of various industries, scope and focus.

In the thesis work "The use of energy-efficient standard Green Zoom for design of residential buildings" (Ekaterina Kutishenko, Fig. 3) the conceptual design of the high-rise, apartment building was developed, its evaluation with the Russian system of energy efficiency and sustainability Green Zoom for civil and industrial construction projects has been made.
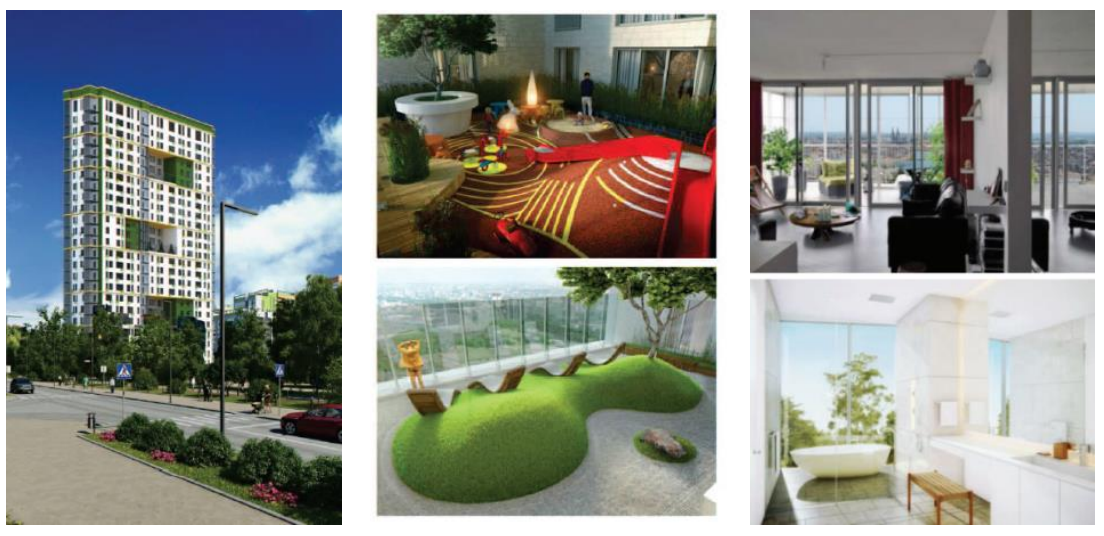

Figure 3

Visualization of the "green" apartment building 
The strategic goal of the Green Zoom standard is to create a favorable living environment with affordable and comfortable housing. The evaluation of buildings according the Green Zoom system is carried out at 9 divisions: architectural and planning solutions, the project location and the organization of transport provision, environmental sustainability territory, water efficiency, energy efficiency, reduction of harmful emissions into the atmosphere, environmentally rational choice of building materials and waste control, the ecology of the internal environment of buildings, innovation in design and regional characteristics.

In the next diploma work (Maria Shevelyova, Fig. 4), the possibilities and advantages of using BIM in a reconstruction of architectural objects are studied using the example of the residential group in Madrid. A joint team of students of the architectural university and the Ural Federal University presented this project at the International Student Contest "Multi-comfort from Saint-Gobain 2017".

At present, many large urban centers are very tight, so architects pay tremendous attention, not to the construction of new facilities, but to the improvement and transformation of existing architectural fund. In this case, BIM as a tool, can bring great effect. BIM is especially important for the restoration of historical architecture objects. It is important to model the general condition of the object, as well as the degree of its wear and tear. In this case, it is better to use not modeling from plans, but scanning of a building with special equipment, since some parameters that may seem insignificant at first glance may turn out to be a destructive factor during reconstruction.

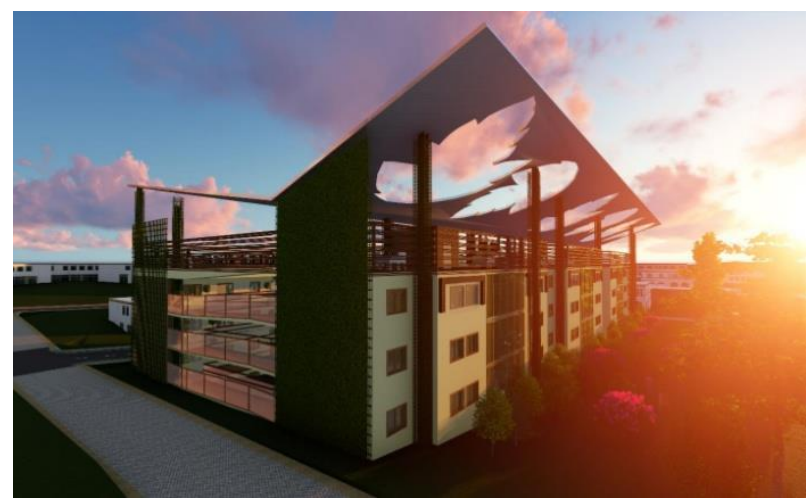

Figure 4

The reconstruction of the residential group in Madrid

The use of BIM in the reconstruction is a fairly new and unexplored direction. Usually, the building information model is applied at all stages of design and construction, including operation and demolition. For planning the reconstruction using BIM, you can also get all the necessary information. The advantages of BIM in the process of building reconstruction are as follows: 
- The reconstructed object already possesses an architectural form and various systems, from which changes begin. In this case, BIM tools allow you to check automatically the object for various collisions, inconsistencies between old and new subsystems. Specifications are generated automatically; various calculations are performed, including cash estimates.

- The ability to model many reconstruction options, including mixing details of different versions.

- The possibility to develop a modification of the object by stages, for example, dismantling of a part of the building, installation of new architectural forms, installation of new systems and so on.

- Thanks to the information model, it is also possible to efficiently make a partial replacement of engineering systems.

- In the BIM model, you can specify the timing of the reconstruction, lay the time schedules and monitor the current state of the structure.

- Computer experimentation. Many worn objects are falling under reconstruction, so their innovating may be disastrous. That is BIM programs allowing reconstruction of various situations for optimizing systems and design solutions.

- Information modeling is also relevant for seismically unstable areas in the restoration of buildings, since bearing structures are most often only reinforced, and not completely reworked.

- BIM allows you to design a reconstruction of any age-related building, taking into account new standards for environmental and energy-saving requirements, thanks to which the facility can get a green certificate.

\section{Conclusions}

The world trend, in the modern construction, corresponds to the ecological, rational design, according to green standards and the application of BIM.

A modern BIM specialist, based on the main property of the BIM, is ready for teamwork in a common information space and should have a sufficient number of competencies to solve professional problems.

To widespread application of BIM and Green BIM technologies, it is necessary to develop the educational standards for teaching them at Universities.

Many architecture and Civil Engineering Universities, in different countries, introduce active and practice-oriented methods for teaching BIM. Herein, we have shown some of the features of these processes.

At the USUAA we teach interdisciplinary specialists, Informatics-Architects, and develop systems allowing us to comprehensively impart the principles of 
environmental design and information modeling, through active practice-oriented methods.

Some results of Green BIM application, in diploma projects related to real architectural and construction objects, in accordance with green standards, are presented in this paper.

\section{References}

[1] Feist, W.: Gestaltungsgrundlagen Passivhäuser, Verlag Das Beispiel, 2000, 143 p. Russian translation: W. Feist, The main provisions on the design of passive houses, Moscow: ACB, 2011, $144 \mathrm{p}$.

[2] Krygiel, E., Nies, B.: Green BIM: Successful Sustainable Design with Building Information Modeling, Wiley Publishing, 2008, 268 p.

[3] Johnny Kwok, Wai Wong, Jason Zhou: Enhancing environmental sustainability over building life cycles through green BIM: A review, Automation in Construction, Volume 57, September 2015, pp. 156-165

[4] Yujie Lu, Zhilei Wu, Ruidong Chang, Yongkui Li: Building Information Modeling (BIM) for Green Buildings: A Critical Review and Future Directions, Automation in Construction, Vol. 83, Nov. 2017, pp. 134-148

[5] Tamer El-Diraby, Thomas Krijnen, Manos Papagelis: BIM-based Collaborative Design and Socio-technical Analytics of Green Buildings, Automation in Construction, Volume 82, October 2017, pp. 59-74

[6] Bahriye Ilhan, Hakan Yaman:. Green Building Assessment Tool (GBAT) for Integrated BIM-based Design Decisions, Automation in Construction, Volume 70, October 2016, pp. 26-37

[7] José Pedro Carvalho, Luís Bragança, Ricardo: Mateus Optimising building sustainability assessment using BIM, Automation in Construction, Volume 102, June 2019, pp. 170-182

[8] Araszkiewicz, K. Green BIM Concept - Scandinavian Inspirations, Archives of Civil Engineering, Vol. LXII, ISSUE I, 2016

[9] Baranyai Bálint, Bachmann Bálint, Kistelegdi István: Simulation-supported Design of a Hungarian National Sports Center, An International Journal for Engineering and Information Sciences, Volume 11, No. 1, 2016, pp. 113127

[10] Shen Jiang, Wang Lei: The Application of BIM in Green Building Energy Saving: Take Helsinki Music Center as an Example, Advanced Materials Research, Volume 935, pp. 3-7

[11] Amarnath Chegu Badrinath, Yun-Tsui Chang, Shang-Hsien Hsieh: An Overview of Global Research Trends in BIM from Analysis of BIM Publications, Proceedings of $16^{\text {th }}$ International Conference on Computing in Civil and Building Engineering (ICCCBE2016), July 6-8, 2016, Osaka, 
Japan, http://www.see.eng.osaka-u.ac.jp/seeit/icccbe2016/Proceedings/Full _Papers/106-140.pdf

[12] Puolitaival Taija, Kestle Linda: Teaching and Learning in AEC Education the Building Information Modelling Factor, Journal of Information Technology in Construction (ITcon), Volume 23, pp. 195-214, http://www.itcon.org/2018/10

[13] Rahman Rahimi A., Ayer Steven K.: Enhancing the Non-technological Skills Required for Effective Building Information Modeling through Problem-Based Learning, Journal of Information Technology in Construction (ITcon), Volume 24, pp. 154-166, http://www.itcon.org/2019/9

[14] Dakhil Ammar, Underwood Jason, Shawi Mustafa Al: Critical Success Competencies for the BIM Implementation Process: UK Construction Clients, Journal of Information Technology in Construction (ITcon), Volume 24, pp. 80-94, http://www.itcon.org/2019/5

[15] Yilmaza Gokcen, Akcameteb Asli, Demirors Onur: A Reference Model for BIM Capability Assessments, Automation in Construction, 101, 2019, pp. 245-263

[16] Oyewole Oluwatosin, Dada Joshua: An Evaluation of Training Needs of the Nigerian Construction Professionals in Adopting Building Information Modelling, Journal of Construction in Developing Countries, 24, № 2, 2019, pp. 63-81, http://web.usm.my/jcdc/current.html; doi.org/10.21315/ jcdc2019.24.2.3

[17] Spryzhkov A. M., Privorotsky D. S., Privorotskaya E. V., Yashina N. A.: Information Modeling and Integrated Implementation of Projects in Crossdisciplinary Course Design for Students of Construction Specialties, Bulletin of the Samara Scientific Center of the Russian Academy of Sciences, Volume 18, No. 4, 2016

[18] Semenov A. A.: An Interdisciplinary Approach to the Training of BIM Specialists, New Information Technologies in Architecture and Construction: Materials of the II All-Russian Scientific and Practical Conference with International Participation. Yekaterinburg: USUAA, 2019, p. 43

[19] Grishina N. M., Chaly Yu. Yu.: Problems and Prospects of BIM in Universities: Development Management in Construction, News of KazGASU, 2017, No. 3 (41)

[20] Zakharova G., Krivonogov A., Petunin A.: The Need for Teaching of Green BIM Technologies in Higher School of XXI Century, Russian Journal of Construction Scince and Technology, Ural Federal University, Institut of Civil Engineering, 2017, Vol. 3, № 1, pp. 74-79 
[21] Zakharova, G., Krivonogov, A.: Building Information Modeling on the Basis of Green Standards for the Purpose of Sustainable Development of Territories, Izvestiya Vuzov, Physics, № 8/2, 2016, pp. 37-40

[22] Krivonogov A., Zakharova G., Kruglikov S., Plotnikov S.: Implementation of BIM-Technologies in the Educational Program of the Architectural University: Matec Web Of Conferences 2018, C. 01001. Conference Proceedings, $9^{\text {th }}$ International Scientific Conference Building Defects 2017, pp. 14-19

[23] BIM Project Execution Planning Guide [Online] Available: http://bim.psu.edu/ (current May 2020) 